\title{
Failure analysis of an elbow tube fitting
}

\author{
Reza A. Mirshams ${ }^{\mathrm{a}, *}$, Mehdy Sabbaghian ${ }^{\mathrm{b}}$ \\ ${ }^{a}$ Department of Engineering Technology/Department of Materials Science, University of North Texas, \\ PO Box 310679, Denton, TX 76203-0679, USA \\ b Mechanical Engineering Department, Louisiana State University, Baton Rouge, LA 70803, USA
}

Received 30 July 2002; accepted 24 August 2002

\begin{abstract}
Safe operation of machinery depends strongly on the design of the system and the employment of proper components and materials. Unique to fluid powered systems are the proper selection of hydraulic lines, fittings, and control valves. This paper describes the cause of fracture in an elbow tube fittings due to deficiencies in the dimensional design and materials selection. The investigation included metallography, fractography, hardness testing and metrology. The results showed that the material was low carbon steel subjected to cold forming and normalized annealing processes during tube production. There were dimensional variations in the tube and the material strenght was low.
\end{abstract}

(C) 2002 Elsevier Science Ltd. All rights reserved.

Keywords: Shear failure; Rupture; Bursting; Hydraulic fitting; Overload

\section{Introduction}

Selection of tube fittings is essential to the proper operation and safe use of hydraulic tubing and related equipment. Inadequate attention to selection of the tube fittings will result in leaking, bursting, or other failure leading to serious bodily injury or property damage. Some of the factors which are involved in the proper selection of tubing are: material of tubing, inside diameter, wall thickness, design criteria and safety factors, temperature, flow, velocity, pressure and corrosion requirements.

Tubes are constructed of different materials. Seamless SAE 1010 fully annealed is the most widely available material for bent and flared tubes. Other materials are stainless steel (302, 303, and/or 304), aluminum alloys (for low pressure), copper tubing (for low pressure or air), and special alloys (for specific corrosion prevention).

Large industrial trash compactors take in loose metal scraps, cans, etc. and compress them to relatively small volume bundles. Hydraulic cylinders at pressures above $17 \mathrm{MPa}$ normally perform the compaction process. At such a high pressure, the design and proper selection of the components play a key role in the safe operation of the machine and protection of personnel against life threatening mishaps. Selection of

* Corresponding author. Tel.: + 1-940-565-4161; fax: + 1-940-565-2666.

E-mail address: mirshams@unt.edu (R.A. Mirshams). 
instruments, the control devices to monitor the operating conditions as well as the proper materials and dimensions of the hydraulic components are all critical issues that can play a role in the integrity of the machine [1,2]. In a particular trash bailer, a 2 inch elbow ruptured in operation and severely injured the operator. The post accident investigation indicated a deficient elbow was employed on the high-pressure side of the system. Additionally, use of an improper pressure indicator and hydraulic control valve contributed to the failure. In this paper, a detailed account of the failure is described.

\section{Experimental procedure and results}

\subsection{Dimensions and observations}

Figs. 1 and 2 illustrate an exemplar new elbow and the subject failed elbow, respectively. The bend angle is close to $90^{\circ}$ (right angle). The outer and inner diameter of the tube, away from the bend, are about 50.00 and $44.50 \mathrm{~mm}$, respectively. Both ends of the tube have welded flanges as shown in Figs. 1 and 2. The tube is seamless. The thickness of the tube was measured using a digital vernier caliper. Three measurements were made at each position identified in, Figs. 3 and 4, by letters A, B, C, D, E, F, and G. The measurements on the top of the stretched side of bend were made by cutting small sections for metallography examination. Table 1 summarizes the average measurements at each position on the tube fitting for the new and failed tubes.

The conventional manufacturing process for tube bending is a cold forming process using special tooling to avoid buckling and folding. The following observations from Table 1 are of interest: (a) the thickness of the new tube is different in the area close to the flange from A to E; (b) there is a $20 \%$ thickness reduction on the outside curvature from point A to point G. Point E, is the original tube, unaffected by the cold form bending and point $\mathrm{G}$ has the maximum stretch due to cold work. In addition, the process caused about $15 \%$ difference in thickness between regions of $\mathrm{A}$ and $\mathrm{E}$ in the new tube, (c) the thickness reduction close to the fracture line is about $32-34 \%$ (comparison of $\mathrm{E}$ with $\mathrm{F}$ and $\mathrm{G}$ ).

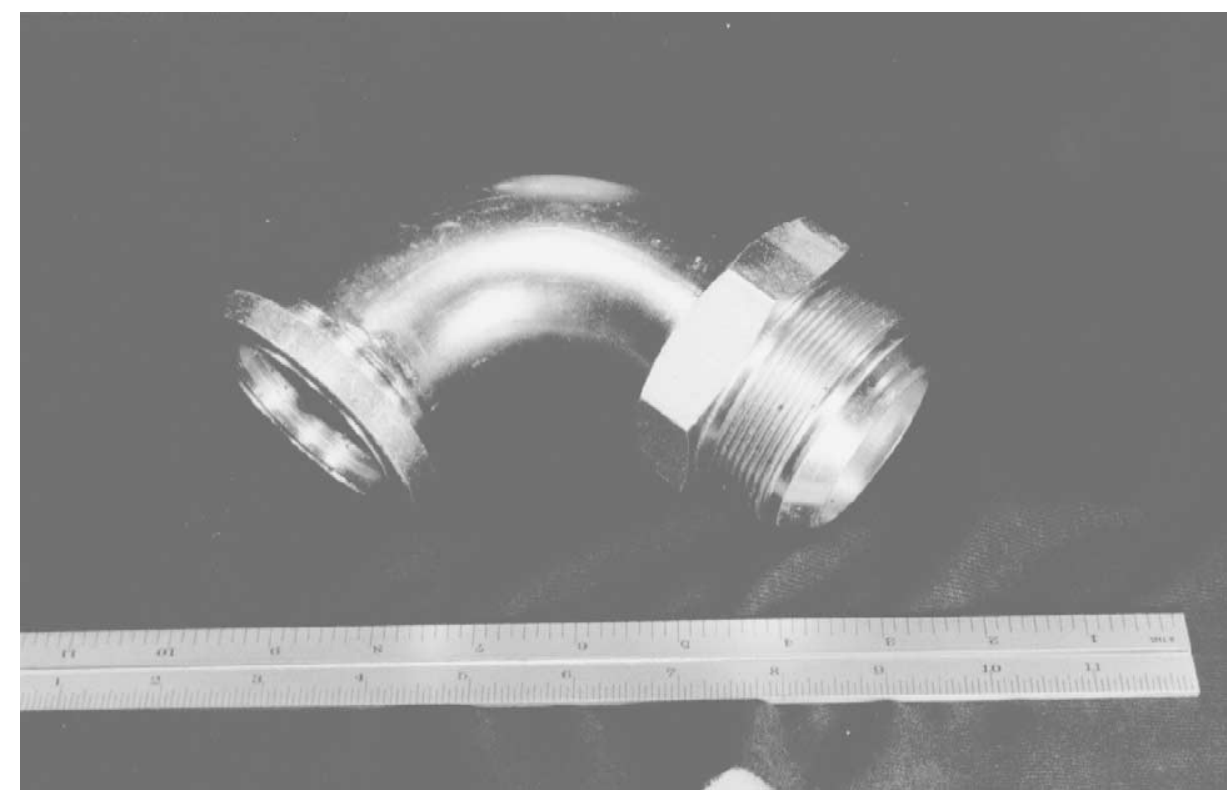

Fig. 1. A new fitting tube. 


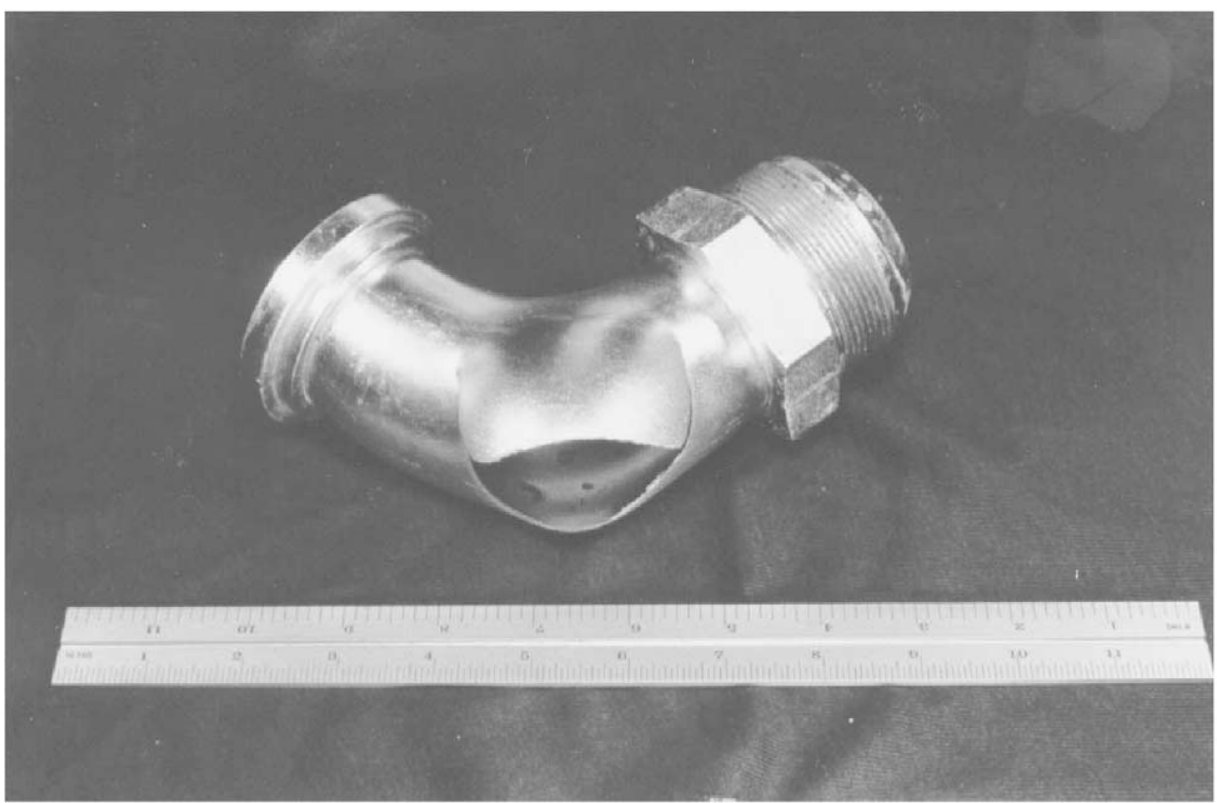

Fig. 2. The failed fitting tube.

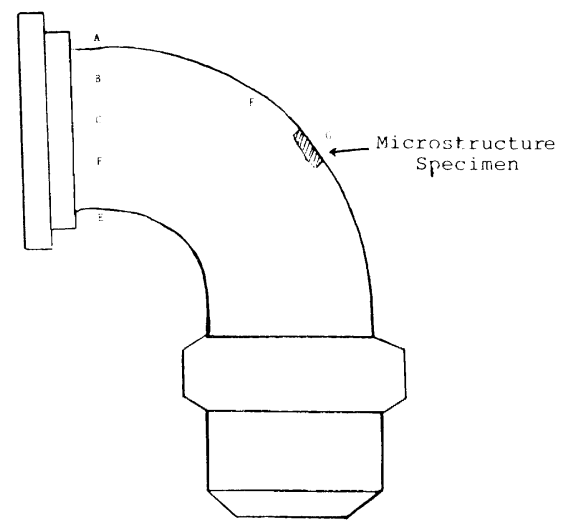

Fig. 3. Sketch of the new fitting tube. The marked area shows location of specimen for microstructure examination. The letters show locations of thickness measurements.

Table 1

Summary of thickness measurements $(\mathrm{mm})$

\begin{tabular}{lllllllr}
\hline & A & B & C & D & E & F & G \\
\hline New & 3.05 & 4.06 & 3.20 & 3.35 & 3.58 & 2.51 & 2.44 \\
Failed & 2.84 & 3.10 & 3.12 & 3.30 & 3.58 & 1.65 & 1.65 \\
\hline
\end{tabular}




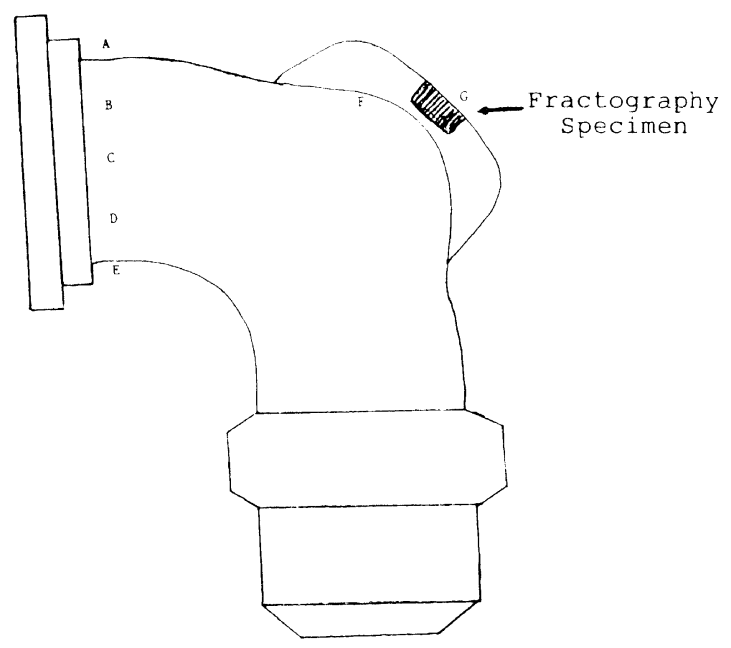

Fig. 4. Sketch of the failed tube. The marked area shows location of specimen for fractography examination. The letters show locations of thickness measurements.

\subsection{Macroscopic and microscopic examinations}

\subsubsection{Macro analysis}

Fracture started in the stretched portion of the tube wall. Bulging due to over stretching from internal pressure is evident (Fig. 2). Occurrence of a localized neck in the place of fracture initiation is visible. The crack has extended beyond the bulged area due to the maintenance of the internal pressure.

\subsubsection{Micro analysis}

2.2.2.1. Optical microscopy. To examine the microstructure, a section was made from the stretched part of the new tube (Fig. 3). A conventional metallography procedure was used to polish and etch the specimen. A 3\% Nital solution was used for etching for about 5 s. Figs. 5 and 6 show the microstructures.

Fig. 5 indicates that the steel was normalized after the bending process. Figs. 5 and 6 show a ferritic microstructure plus a few patches of pearlite. Grains have not elongated in the bending axis. Non uniformity in size and distribution is evident. Examination at higher magnification, Fig. 5, shows a thick precipitation in the grain boundary. No chemical analysis was carried out for the grain boundary compositions. The small amount of pearlite in Fig. 6 indicates that the carbon content should be in the range $0.10-0.12 \%$. The microstructure indicates the material is a low plain carbon steel in the range of $\mathrm{C} 1010$ to C1015 [3,4].

2.2.2.2. Scanning electron microscopy. The fracture surface was examined carefully. Bulging of the tube was evident on the outer side of the bend. The fracture line was on the top of stretched part of the tube and normal to the circumference. The line of fracture extended on the top of the tube and then extended to one side. A fractography sample was made from the fracture side on the top of the bulge, for examination of the fracture surface using a scanning electron microscope (SEM).

Fractography of the fractured section from the bulged area shows a ductile mode of fracture in which dimples are mostly small and shallow, typical of shear deformation and fracture. Elongated dimples are observed in some regions. This could be attributed to orientation of grains in different regions. The inhomogeneous microstructure is the result of non uniformity of grain sizes and possible precipitation of a ductile phase in grain boundaries. The inhomogeneous microstructure through the wall thickness could 


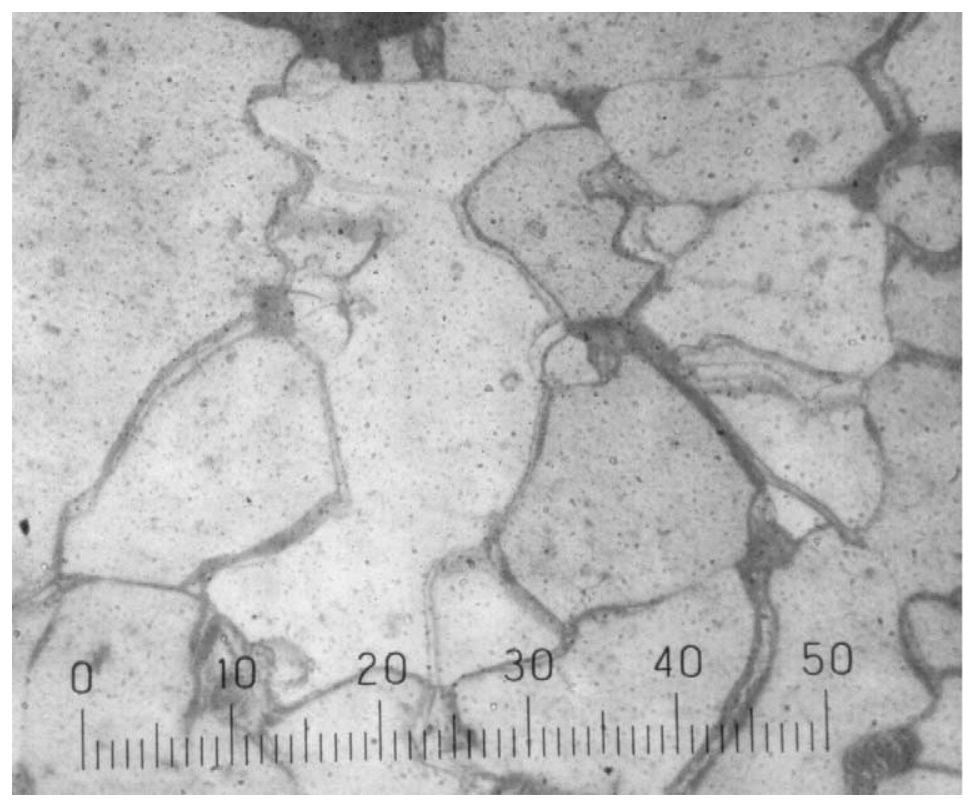

Fig. 5. Microstructure of the new tube at the $\mathrm{G}$ magnification $600 \mathrm{X}$.

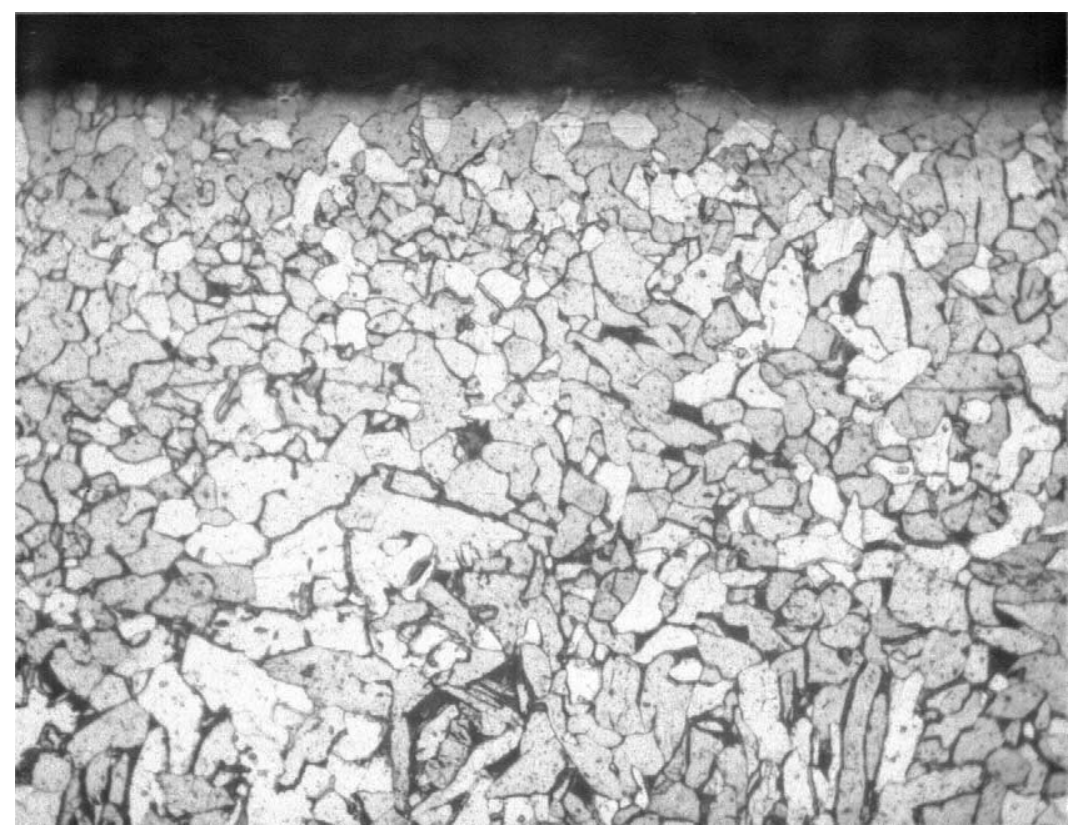

Fig. 6. Microstructure of the new tube at G, magnification 100X. 


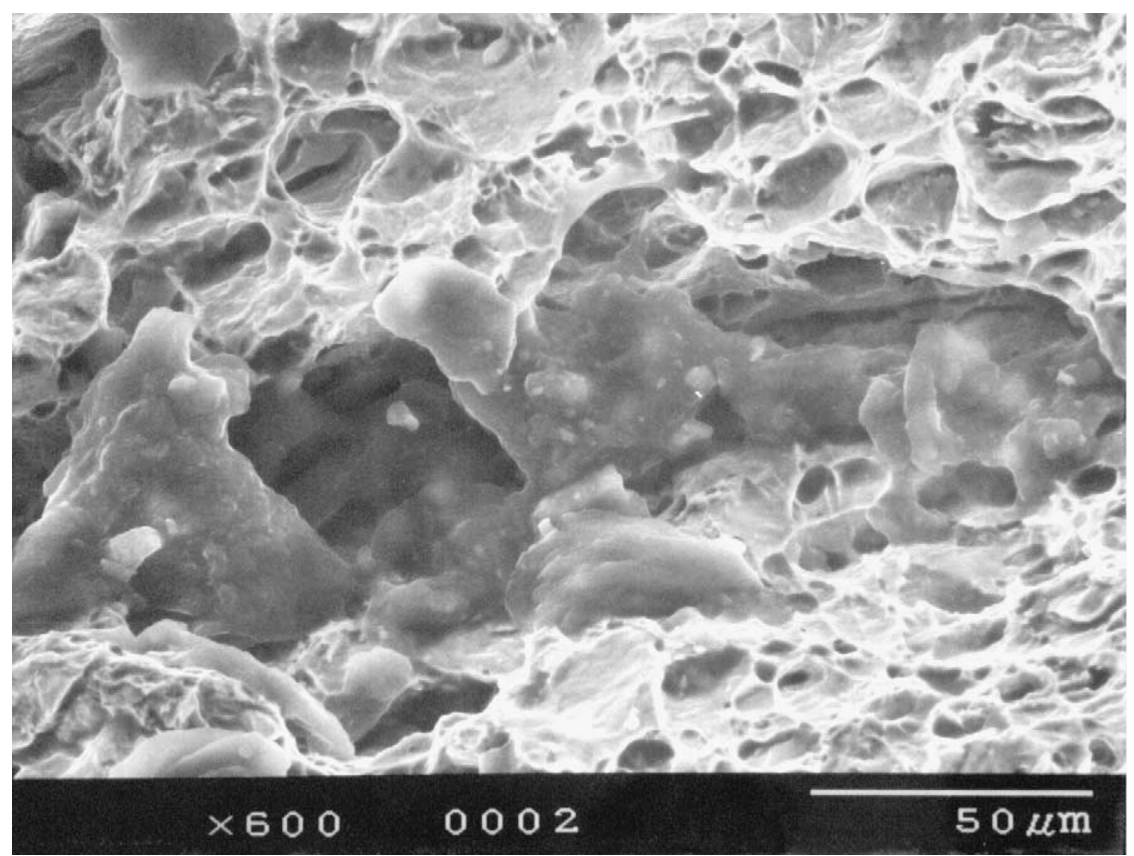

Fig. 7. SEM photomicrograph of the fracture surface shows shear mode fracture.

easily provide deficiencies in the material integrity. This will lead to premature failure initiation [5]. Fig. 7 is a representative fracture surface by SEM.

\subsection{Hardness measurements}

Rockwell "B" hardness (HRB) measurements were made on the region $G$ of the tubes (Figs. 3 and 4). A brass standard block used to check the calibration of the Rockwell "B" machine. The block has 41 HRB. The results indicated $38 \mathrm{HRB}$ and $77 \mathrm{HRB}$ for the new and burst tubes, respectively. The increase in hardness comes from the work hardening due to the deformation and bulging in the tube. ASTM Designation: E 140-95 conversion tables, to convert HRB to Brinell hardness (HB), provided a value below 100 HB for $38 \mathrm{HRB}$ (not exact number) and $141 \mathrm{HB}$ for $77 \mathrm{HRB}[6]$.

\section{Conclusions}

On the basis of the macroscopic and microscopic evidence and the background information, the following conclusions could be drawn:

1. The results indicate the material was too soft for this application.

2. The normalizing heat treatment created a non-uniform grain size, grain distribution, and grain boundary precipitation.

3. The insufficient tube wall thickness at the bend contributed to the failure.

4. It seems that the wall thickness and materials properties were not adequately considered in the design analysis. 


\section{References}

[1] Hertzburg RW. Deformation and fracture mechanics of engineering materials, 3rd ed. John Wiley; 1989.

[2] Metals handbook. Properties and selection: irons, steels, and high-performance alloys, vol. 1, 10th ed. ASM-International; 1990.

[3] Krauss G. Steels; heat treatment and processing principles. ASM International; 1990.

[4] Metals handbook, Metallography and microstructures, vol. 9, 9th ed, ASM- International; 1985.

[5] Metals handbook, Fractography, vol. 12, 9th ed, ASM- International; 1985.

[6] Annual book of ASTM standards, Metals test methods and analytical procedures, vol. 03.01. 1995. 